\title{
PENGOLAHAN LIMBAH PLASTIK JENIS POL YETHELENE TEREPHALATE (PET) DAN HIGH DENSITY POL YETHELENE (HDPE) MENJADI BAHAN BAKAR MINYAK
}

The Conversion of Waste Plastic Type Polyethelene Terephalate (PET) and High Density Polyethelene (HDPE) to be Material Burn Oil Taufik Arjal ${ }^{1}$, Rafidah ${ }^{2}$

1,2Jurusan Kesehatan Lingkungan Politeknik Kemenkes Makassar (taufikcnbl08@gmail.com)

\begin{abstract}
According to Industry Plastic Indonesian (INAPLAS) and Body Center Statistics (BPS), plastic waste in indonesian reaches about 64 million ton/year assocition where much as 3,2 million tons are p;astic waste discarded to the sea. According to thr same source, plastic bags wasted as much as 10 million pieces per year or many as 85.000 ton plastic bags. The purpose of this reaches was find out the ability plastic waste treament using by pyrolysis method become FUEL OIL. This type of reachers is kuasi eksperiment. Knowing the ability of the tool produce fuil oil and to know the amount decline garbage with utilization waste plastic to be material burn oil (BBM). The pyrolisis methood in this reaches was able to produce of material burn oil (BBM) are : PET $=14 \mathrm{ml}, \mathrm{HDPE}=12,6 \mathrm{ml}, \mathrm{PET}$ and HDPE $=12 \mathrm{ml}$, by decline of solid plastic waste as much as : 0,4 or $40 \%$ and PET, HDPE=0,5 or $50 \%$ of each $1 \mathrm{~kg}$ plastic. The conclusion of this study is that the pyrolysis device is not capable of producing $\leq 1200 \mathrm{ml}$ of fuel oil (BBM). For this reason, it is hoped that further researchers need to carry out further research on the effect of temperature on the plastic pyrolysis process, the type of fraction in the pyrolysis oil, and if it is developed on a production scale it needs to be examined again using a better reactor, so that the processing process can take place continuously.
\end{abstract}

Keywords: Waste Plastic, Polyethelene Terephalate (PET), High Density Polyethelene (HDPE), Material Burn Oil

\section{ABSTRAK}

Menurut Asosiasi Industri Plastik Indonesia (INAPLAS) dan Badan Pusat Statistik (BPS), sampah plastik di Indonesia mencapai 64 juta ton/ tahun dimana sebanyak 3,2 juta ton merupakan sampah plastik yang dibuang ke laut . Menurut sumber yang sama, kantong plastik yang terbuang ke lingkungan sebanyak 10 milliar lembar per tahun atau sebanyak 85.000 ton kantong plastik. Tujuan penelitian ini adalah untuk mengetahui kemampuan alat pengolahan limbah plastik dengan menggunakan metode pirolisis menjadi bahan bakar minyak. Jenis penelitian ini merupakan kuasi eksperimen. Mengetahui kemampuan alat dalam menghasilkan bahan bakar minyak dan untuk mengetahui banyaknya penurunan sampah dengan pemanfaatan limbah plastik menjadi Bahan Bakar Minyak (BBM). Hasil penelitian ini yaitu dapat menghasilkan Bahan Bakar Minyak (BBM) yaitu sebanyak : PET=14,3 ml, HDPE=12,6 ml, PET dan HDPE=12 ml dengan penurunan padatan sampah plastik sebanyak : PET=0,5 atau 50\%, HDPE=0,4 atau 40\%, serta PET dan HDPE=0,5 atau $50 \%$ dari masing-masing $1 \mathrm{~kg}$ plastik. Kesimpulan penelitian ini adalah alat pirolisator Tidak mampu menghasilkan Bahan Bakar Minyak (BBM) sebanyak $\leq 1200 \mathrm{ml}$. Untuk itu, diharapkan peneliti selanjutnya perlu melakukan penelitian lebih lanjut mengenai pengaruh suhu terhadap proses pirolisis plastik, jenis fraksi pada minyak hasil pirolisis, dan apabila dikembangkan dalam skala produksi maka perlu diteliti lagi menggunakan reaktor yang lebih baik, sehingga proses pengolahan bisa berlangsung terus menerus.

Kata kunci: Limbah Plastik, Polyethelene Terephalate (PET), High Density Polyethelene (HDPE), Bahan Bakar Minyak

\section{PENDAHULUAN}

Sampah plastik adalah salah satu sumber pencemaran lingkungan hidup di Indonesia. Plastik merupakan produk serbaguna, ringan, fleksibel, tahan kelembaban, kuat, dan relatif murah. Dan metupakan salah satu barang yang paling sering digunakan oleh manusia untuk pemenuhan keperluan hidupnya adalah plastik.

Pembuangan sampah-sampah plastik ke dalam air dan tanah sering terjadi, hal tersebut memicu kerusakan alam karena sampah plastik terbuat dari bahan anorganik, umumnya sulit untuk di degradasikan ( diuraikan ) mikroorganisme. Hal ini akan menimbulkan masalah pencemaran lingkungan. Selain itu ketika di bakar sampah plastik tersebut akan menghasilkan gas hidrogen sulfida yang dapat menjadi racun bagi lingkungan dan hal ini sangat jelas akan merugikan masyarakat, terlebih lagi jika sampah plastik terdapat senyawa klorida $(\mathrm{Cl})$ yang dapat menghasilkan dioksin( penyebab kanker ) jika di bakar pada suhu rendah. Indonesia merupakan Negara penghasil sampah plastik terbanyak ke dua setelah Negara Cina. Hal ini karena kurangnya pengolahan yang di lakukan sehingga sampah tersebut menumpuk di pembuangan akhir. Menurut Asosiasi Industri Plastik Indonesia (INAPLAS) dan Badan Pusat Statistik (BPS), sampah plastik di Indonesia mencapai 64 juta ton/ tahun dimana sebanyak 3,2 juta ton merupakan sampah plastik yang dibuang ke laut . Menurut sumber yang sama,, kantong plastik yang terbuang ke lingkungan sebanyak 10 milliar lembar per tahun atau sebanyak 85.000 ton kantong plastik. Berdasarkan asumsi Kementerian Lingkungan Hidup (KLH) setiap hari penduduk Indonesia menghasilkan $0,8 \mathrm{~kg}$ sampah per orang atau secara total 
Jurnal Sulolipu : Media Komunikasi Sivitas Akademika dan Masyarakat

Vol. 20 No.2 2020

e-issn : 2622-6960, p-issn : 0854-624X

sebanyak 189 ribu ton sampah/hari. Dari jumlah tersebut $15 \%$ berupa sampah plastik atau sejumlah 28,4 ribu ton sampah plastik/hari (Sumarni,2008).

Berdasarkan Data dari Dinas Pertamanan dan Kebersihan Kota Makassar (2014) jumlah total timbulan sampah di kota Makassar sebesar $4.494,86 / \mathrm{m}^{3}$, dengan jumlah timbulan plastik sebesar $425,66 / \mathrm{m}^{3}$ setiap Bulan. Berdasarkan data dari Greeneration (2017) Khusus di Kota Makassar dengan jumlah penduduk mencapai 1,4 juta jiwa, menghasilkan sekitar 4500 kubik sampah setiap harinya, volume sampah di Kota Makassar bertambah 200 ton per hari, di mana setiap bulannya sampah berkisar antara 600 ton hingga 800 ton, sehingga dapat disimpulkan kalau volume sampah di Kota Makassar cukup tinggi dengan memproduksi sampah hingga 550 ton, atau sekira 4.000 meter kubik per hari. Jumlah sampah di Indonesia, khususnya Makassar akan terus meningkat jika penanganan sampah belum ditangani secara serius. Diprediksikan, pada 2019, produksi sampah di Indonesia akan mencapai 67,1 juta ton sampah per tahun. Sedangkan data yang di peroleh dari SIPSN ( Sistem Informasi Pengolahan Sampah Nasional, 2018 ) tepatnya di kota Makassar dengan luas wilayah $175.77 \mathrm{Km}^{2}$ dengan jumlah jiwa per 2018 adalah 1.469.601 jiwa dapat menghasilkan 1.425 .00 ton/hari dengan persentasi sampah plastik sebesar $16.29 \%$.

Minyak mentah adalah bahan utama dari plastik dan sebagian besar bahan kimia. Dari total 100 juta ton plastik diproduksi setiap tahun di seluruh dunia, 25 juta ton dibuang. Dengan membuang jumlah berat seperti limbah plastik, banyak membuang energi dalam bentuk minyak mentah yang digunakan untuk membuat plastik. Energi yang terbuang dapat dipulihkan kembali menggunakan proses Pirolisis. Proses ini menghemat sumber energi konvensional yaitu minyak mentah. $1 \mathrm{~kg}$ limbah plastik menghasilkan 1 liter bahan dasar minyak atau minyak mentah ketika diolah jadi premium atau solar. Melalui proses pemanasan, hidrokarbon yangmerupakan komponen penyusun plastik akan menguap menjadi gas. Selanjutnya gas tersebut dikondensasi dan terbentuklah zat cair yang kualitasnya hampir sama dengan bahan bakar (Bajus dan Hajekova, 2010).

$$
\text { Menurut penelitian }
$$

Hendra Prasetyo, Rudhiyanto, Ilham Eka Fitrianto ( 2013 ) "Mesin Pengolahan Limbah Sampah Plastik Menjadi Bahan Bakar Alternatif" adapun hasil yang di dapatkan dengan sampel botol plastik dengan massa 500 gram yaitu 0,5 I dan sampel plastik kresek dengan massa 500 gram yaitu 0,5 I dengan suhu 200 dan $300^{\circ} \mathrm{C}$.

Dari penelitian Nasrun, Eddy, dan Inggit Sari(2015) "Pengolahan Limbah Kantong Plastik Jenis Kresek Menjadi Bahan Bakar Menggunakan Proses Pirolisis" di dapatkan hasil dengan bahan baku kantong kresek massa 500 gram terjadi pada suhu 260-300ㄷ dan waktu operasi 0-60 menit dengan jumlah nilai kalor sebesar $10.541,75$ $\mathrm{kkal} / \mathrm{kg}$.

Menurut penelitian Raden Sagera Wasesa, (2016) "Pengolahan Sampah Plastik Menjadi Bahan Bakar Dengan Alat Pengolahan Sampah Plastik Fixed-Bed Reaktor, Dua Kondensor" didapatkan hasil bahan baku plastik jenis LDPE dengan massa 1000 gram yaitu $1100 \mathrm{ml}$ bahan bakar. Sedangkan penelitian Ekky Wahyudi, Zultinia, Edy Saputra, (2016) "Pengolahan

Sampah Plastik Polipropilena (Pp) Menjadi Bahan Bakar Minyak Dengan Metode Perangkahan Katalik Menggunakan Katalis Sintetis" didapatkan hasil jenis plastik (PP ) dengan massa 100 gram yaitu $120 \mathrm{ml}$ dengan nilai kalor $10.884 \mathrm{kal} / \mathrm{g}$ dengan suhu $350-450$ $\stackrel{\circ}{ } \mathrm{C}$.

Menurut penelitian Ahmad Ridho Ismail, (2017) "Pemanfaatan Limbah Plastik Menjadi Bahan Bakar Minyak" didapatkan hasil bahan baku plastik jenis PET dengan massa 1000 gram yaitu $353,14 \mathrm{ml}$ bahan bakar pada suhu $100-270{ }^{\circ} \mathrm{C}$.

\section{METODE}

Penelitian ini merupakan penelitian kuasi eksperimen skala untuk mengetahui kemampuan alat pengolahan limbah plastik dalam menghasilkan Bahan Bakar Minyak (BBM) selama 60 menit pada 3 sampel dengan 3 kali percobaan.

Penelitian dilakukan di Workshop Politeknik Kesehatan Makassar Jurusan Kesehatan Lingkungan. Tahapan penelitian ini yaitu : 1) Tahap persiapan, meliputi observasi pendahuluan dan menyusun proposal yang berlangsung pada bulan Desember 2018 sampai Januari 2019 dan 2) Tahap pelaksanaan, meliputi kegiatan penelitian yang berlangsung pada bulan April sampai Juni 2019.

\section{Bahan dan Alat}

\section{Bahan}

a. Limbah plastik jenis PET

b. Limbah Plastik jenis HDPE

c. Limbah Plastik jenis PET dan HDPE.

2. Alat

a. 1 buah drum almunium besi/baja diameter $40 \mathrm{~cm}$.

b. 1 buah pipa almunium besi/baja 3/4 inci. 
c. 1 buah pipa almunium besi/baja 3 inci.

d. 1 buah Las.

e. 1 buah gergaji besi/

f. 2 buah sambungan pipa almunium besi/baja $L^{3} / 4$.

g. 1 Buah pompa air kecil.

h. 1 buah selang.

i. 1 buah wadah air ( ember ) dsb.

j. 1 buah kran air.

k. Kompor gas

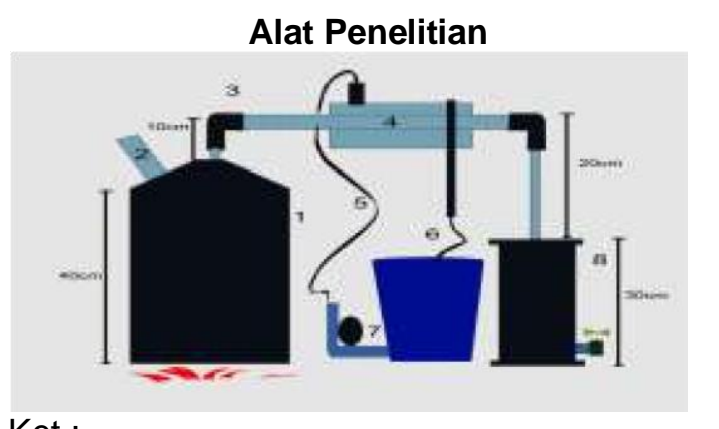

Ket :

1. Wadah pirolisator

2. Tempat masuk sampah

3. Pipa besi

4. Tabung kondensor

5. Selang

6. Wadah air / ember

7. Pompa

8. Tabung penampung minyak

9. Kran

\section{LANGKAH-LANGKAH PENELITIAN}

1. Proses Pengumpulan Sampah dikumpulkan berdasarkan jenisnya yaitu PET dan HDPE.

2. Proses Pengolahan

a. Limbah plastik dikumpulkan sesuai dengan kebutuhan setelah itu dicincang dengan ukuran $\geq 3 \mathrm{~cm}$, dan dicuci dengan bersih lalu dikeringkan

b. Masukkan sampel (limbah plastik) yang sudah di cincang dan di keringkan kedalam wadah pirolisator yang berbentuk tabung kedap udara dari bahan stainless stell/ drum, kemudian tutup rapat agar asap tidak keluar.

c. Setelah itu panaskan wadah pirolisator tersebut selama 60 menit hingga plastik yang didalam wadah melebur dan menghasilkan asap

d. Kemudian dari wadah pirolisator asap menuju ke tabung kondensor melalui pipa.

e. Tabung kondensor dengan panjang $30 \mathrm{~cm}$ berisi air yang di alirkan dengan menggunakan pompa dari wadah yang berisi air, yang dimana tabung kondensor berfungsi sebagai tempat kondensasi asap (pendinginan asap) yang akan merubah menjadi asap cair.

f. Asap cair dari hasil kondensasi akan ditampung di tempat penampungan, yang keluar melalui kran outlet.

g. Kemudian dinginkan asap cair tersebut.

h. Ulangi sebanyak 3 kali replikasi pada 3 sampel

i. Dinginkan alat pirolisis.

j. Lihat dan hitung sisa padatan yang ada pada tabung pirolisis.

k. Bersihkan dan rapikan alat pirolisis.

\section{PENGOLAHAN DAN ANALISIS DATA}

Teknik analisa data dilakukan secara deskriptif untuk mengetahui ada atau tidaknya asap cair (minyak) yang dihasilkan pada proses pirolisis dan digambarkan dalam bentuk tabel atau grafik.

\section{HASIL}

1. Hasil Minyak Pirolisis plastik selama percobaan

Berdasarkan hasil eksperimen pengolahan limbah plastik yang paling banyak menghasilkan minyak yaitu Limbah plastik jenis PET dengan jumlah minyak sebanyak 14,2 $\mathrm{ml}$ sedangkan limbah plastik yang paling sedikit menghasilkan minyak adalah gabungan limbah plastik jenis PET dan HDPE dengan jumlah minyak sebanyak $12 \mathrm{ml}$. (table 1)

\section{Tabel 1}

Hasil Minyak Pirolisis plastik PET \& HDPE 2019

\begin{tabular}{clccccc}
\hline No & Jenis & \multicolumn{3}{c}{ Hasil $(\mathrm{ml})$} & $\sum$ & Suhu \\
\cline { 3 - 5 } & Plastik & 1 & 2 & 3 & $(\mathrm{ml})$ & $\left({ }^{\circ} \mathrm{C}\right)$ \\
\hline 1 & PET & 14 & 14 & 16 & 14.3 & 150 \\
2 & HDPE & 11 & 13 & 14 & 12.6 & 150 \\
3 & PET \& & 12 & 12 & 12 & 12 & 150 \\
& HDPE & & & & & \\
\hline
\end{tabular}

Sumber : Data Primer

Pengolahan limbah plastik yang paling banyak mengalami penurunan berat adalah limbah plastik jenis PET dan gabungan dari limbah plastik jenis PET dan HDPE dengan persentase jumlah penurunan berat sampel sebesar $0,5 \mathrm{~kg}$ atau sebanyak $50 \%$ sedangkan penurunan berat paling sedikit adalah limbah plastik jenis HDPE dengan persentase jumlah penurunan berat sampel sebesar $0,4 \mathrm{~kg}$ atau sebanyak $40 \%$. (tabel 2 ) 
Jurnal Sulolipu : Media Komunikasi Sivitas Akademika dan Masyarakat

Vol. 20 No.2 2020

e-issn : 2622-6960, p-issn : 0854-624X

Tabel 2

Sisa Padatan Hasil Pirolisis plastik PET \& HDPE 2019

\begin{tabular}{|c|c|c|c|c|c|c|c|c|}
\hline \multirow{2}{*}{$\begin{array}{l}\mathrm{N} \\
\mathrm{O}\end{array}$} & \multirow[b]{2}{*}{$\begin{array}{c}\text { Jeni } \\
\text { s } \\
\text { Pla } \\
\text { stik }\end{array}$} & \multirow{2}{*}{$\begin{array}{l}\text { Ber } \\
\text { at } \\
\text { Pla } \\
\text { stik } \\
(\mathrm{Kg} \\
)^{2}\end{array}$} & \multicolumn{3}{|c|}{$\begin{array}{c}\text { Sisa } \\
\text { Padatan }\end{array}$} & \multirow[b]{2}{*}{$\Sigma$} & \multirow{2}{*}{$\begin{array}{c}\text { Penur } \\
\text { unan } \\
\text { Padat } \\
\text { an } \\
(\mathrm{kg})\end{array}$} & \multirow{2}{*}{$\begin{array}{c}\text { Perse } \\
n \\
\text { tase } \\
\text { Penur } \\
\text { unan } \\
(\%)\end{array}$} \\
\hline & & & 1 & 2 & 3 & & & \\
\hline 1 & $\begin{array}{l}\mathrm{PE} \\
\mathrm{T}\end{array}$ & 1 & $\begin{array}{l}0 . \\
5\end{array}$ & $\begin{array}{l}0 \\
4\end{array}$ & $\begin{array}{l}0 . \\
5\end{array}$ & $\begin{array}{l}0 . \\
6\end{array}$ & 0.5 & 50 \\
\hline 2 & $\begin{array}{l}\mathrm{HD} \\
\mathrm{PE}\end{array}$ & 1 & $\begin{array}{l}0 . \\
6\end{array}$ & $\begin{array}{l}0 \\
6\end{array}$ & $\begin{array}{l}0 . \\
5\end{array}$ & $\begin{array}{l}0 . \\
6\end{array}$ & 0.4 & 40 \\
\hline 3 & $\begin{array}{l}\mathrm{PE} \\
T \& \\
\mathrm{HD} \\
\mathrm{PE}\end{array}$ & 1 & $\begin{array}{l}0 . \\
5\end{array}$ & $\begin{array}{l}0 . \\
5\end{array}$ & $\begin{array}{l}0 . \\
5\end{array}$ & $\begin{array}{l}0 . \\
4\end{array}$ & 0.5 & 50 \\
\hline
\end{tabular}

Sumber : Data Primer

\section{PEMBAHASAN}

Pirolisis berasal dari kata pyro (fire/api) Lyo (loosening/Pelepasan) untuk dekomposisi termal dari suatu bahan organik. Jadi pirolisis adalah proses konfersi dari suatu bahan organik pada suhu tinggi dan terurai menjadi ikatan molekul yang lebih kecil. Pirolisis merupakan suatu bentuk insenerasi yang menguraikan bahan organik secara kimia melalui pemanasan dengan mengalirkan nitrogen sebagai gas inert.

Pada saat proses pengolahan limbah plastik sangat penting untuk memperhatikan setiap komponen dari alat dan bahan yang di gunakan saat proses berlangsung seperti :

1. Wadah Pirolisis

Sebelum melaksanakan penelitian maka perlu dilakukan pengecekan terhadap wadah pirolisis untuk memastikan bahwa tabung tidak mengelami kebecoran saat akan di gunakan pada proses pengolahan limbah plastik karna saat proses pengolahan berlangsung tabung harus kedap udara agar asap dari pemanasan sampah plastik bisa melalui satu jalur saat keluar dari wadah pirolisis yaitu menuju pipa yang akan melalui tabung kondensor atau tabung pendingin.

2. Tabung Kondensor (Pendingin)

$$
\text { Pada saat proses pirolisis }
$$

berlangsung sangat penting untuk selalu mengamati air dalam tabung kondensor agar tetap dingin karena hal ini sangat berpengaruh terhadap hasil yang akan di dapatkan pada saat proses berlangsung.Air dalam tabung harus tetap berotasi agar suhunya dapat terjaga agar tetap dingin, karena saat air tidak berotasi di tabung kondensor maka air tersebut akan panas dan proses penguapan dari asap menjadi minyak tidak optimal dan akan berdampak pada hasil yang $\mathrm{d}$ dapatkan.

Berdasarkan dari proses pirolisis, dapat di ketahui bahwa:

1. Alat Pirolisis tidak dapat menghasilkan minyak sebanyak $\leq 1200 \mathrm{ml}$ dengan sampel limbah plastik jenis PET

Hal ini terjadi karena suhu pada saat proses pengolahan limbah plastik menjadi bahan bakar minyak kurang tinggi, sedangkan peran suhu pada proses pirolisis sangat mempengaruhi waktu termal,seiring waktu reaksi dan suhu di naikkan komposisi dari produk pirolisis berkembang menjadi komponen yang lebih stabil.Dekomposisi limbah plastik di jabarkan sebagai berikut: $100200^{\circ} \mathrm{C}$ pengeringan dengan pemanasan (dehidrasi), $250^{\circ} \mathrm{C}$ hilangnya cairan dan carbon dioksida (evolusi hydrogen), $340^{\circ} \mathrm{C}$ putusnya rantai carbon makromolekul, $380^{\circ} \mathrm{C}$ tahap pirolisis, $400^{\circ} \mathrm{C}$ pecahnya rantai $\mathrm{C}-\mathrm{O}$ dan $\mathrm{C}-$ $\mathrm{H}$.

Penelitian ini sejalan dengan penelitian Untoro Budi Surono, (2016) yaitu Pengolahan Sampah Plastik Jenis PP, PET dan PE Menjadi Bahan Bakar Minyak dan Karakteristiknya penelitian ini diketahui bahwa plastik jenis PET (Polypropylene Terephtalate) tidak menghasilkan minyak sama sekali. Material yang keluar dari kondenser semacam serbuk berwarna kekuningkuningan. Bahkan serbuk ini menempel di sepanjang saluran pipa. Dari hasil ini diketahui bahwa plastik tipe PET tidak potensial untuk diolah menjadi bahan bakar minyak.

Berbeda dengan penelitian
Ahmad Ridho Ismail, (2017) "Pemanfaatan Limbah Plastik Menjadi Bahan Bakar Minyak" didapatkan hasil bahan baku plastik jenis PET dengan massa 1000 gram yaitu $353,14 \mathrm{ml}$ bahan bakar pada suhu 100-270 ${ }^{\circ} \mathrm{C}$.

Selain proses pemanasan proses penguapan juga sangat menentukan hasil dari pengolahan tersebut oleh karena itu sangat pentig untuk memperhatikan tabung kondensor yang menjadi tempat pertukaraan antara asap menjadi cairan.hal ini telah di buktikan oleh Mafruddin, Darma Untung Surya, dan Nuryanto Ahmad (2017) dalam penelitiannya yang berjudul "Pengaruh Geometri Pipa Kondensor Terhadap Perpindahan Panas Pada Destilasi Minyak Plastik" dengan hasil penelitian 
yang di dapatkan adalah Pipa yang menghailkan minyak plastik paling banyak yaitu $4,5 \mathrm{~L}$ pada pipa diameter 0,25 inc dengan geometri $20 \mathrm{~cm}$.

Hal ini juga akan sangat berpengaruh pada suhu saat proses pembakaran pengolahan limbah plastik menjadi bahan bakar minyak, sedangkan peran suhu pada proses pirolisis sangat mempengaruhi hasil, seiring waktu reaksi dan suhu di naikkan komposisi dari produk pirolisis berkembangang menjadi komponen yang lebih stabil. Dekomposisi limbah plastik di jabarkan sebagai berikut: $100-200^{\circ} \mathrm{C}$ pengeringan dengan pemanasan (dehidrasi), $250^{\circ} \mathrm{C}$ hilangnya cairan dan carbon dioksida (evolusi hydrogen), $340^{\circ} \mathrm{C}$ putusnya rantai carbon makromolekul, $380^{\circ} \mathrm{C}$ tahap pirolisis, $400^{\circ} \mathrm{C}$ pecahnya rantai $\mathrm{C}-\mathrm{O}$ dan $\mathrm{C}-\mathrm{H}$. Pengaruh suhu pada proses pirolisis sangat besar, kenaikan suhu menyebabkan bahan yang mudah menguap semakin besar sehingga plastik yang terdekomposisi lebih optimal dan dapat menghasilkan kenaikan hasil minyak pada saat proses berlangsung.

2. Alat Pirolisis tidak mampu menghasilkan minyak sebanyak $\leq 1200 \mathrm{ml}$ dengan sampel limbah plastik jenis HDPE

Pengaruh suhu pada proses pirolisis sangat besar, kenaikan suhu menyebabkan bahan yang mudah menguap semakin besar sehingga plastik yang terdekomposisi lebih optimal dan dapat menghasilkan kenaikan hasil minyak pada saat proses berlangsung.

Penelitian ini sejalan dengan penelitian yang dilakukan oleh Aprian Ramadhan P. dan Munawar Ali (2015) mengenai pengolahan sampah plastik menjadi minyak dengan kapasitas 2000 gram atau $2 \mathrm{~kg}$. Adapun hasil kenaikan produknya yaitu pada menit ke 10 produk yang dihasilkan $5 \mathrm{ml}$, menit ke 20 sebanyak $6,92 \mathrm{ml}$, menit ke 30 sebanyak $9,7 \mathrm{ml}$, menit ke 40 sebanyak 11,26 ml, dan menit ke 60 sebanyak 17,24 ml.

$$
\text { Pada penelitian Ekky }
$$

Wahyudi, Zultinia, Edy Saputra, (2016) Pengolahan Sampah Plastik Polipropilena (Pp) Menjadi Bahan Bakar Minyak Dengan Metode Perangkahan Katalik Menggunakan Katalis Sintetis" mendapat hasil dari jenis plastik (PP) dengan massa 100 gram mendapatkan volume minyak yg lebih banyak yaitu 120 $\mathrm{ml}$ dengan nilai kalor $10.884 \mathrm{kal} / \mathrm{g}$ dengan suhu $350-450 \stackrel{\circ}{\mathrm{C}}$,
Suhu pada saat proses
pengolahan limbah harus sangat diperhatikan agar tetap stabil pada titik didih yang cukup tinggi untuk membantu proses dekomposisi lebih cepat dan dapat menghasilkan minyak lebih banyak.

3. Alat Pirolisis tidak mampu menghasilkan minyak sebanyak $\leq 1200 \mathrm{ml}$ dengan sampel limbah plastik jenis PET dan HDPE

PET memiliki kode angka 1 adalah polimer hasil kondensasi yang umum, sedangkan HDPE memiliki kode angka 2 termaksud dalam kategori ikatan antar molekulnya terjadi bersilang, bentuk ikatan seperti itu memiliki ketahanan suhu yang tinggi sehingga pada suhu rendah proses pengolahan limbah plastik akan menghasilkan sedikit minyak.

Berbeda dengan penelitian Endang K, dan Mukhtar G (2016) "Pengolahan Sampah Plastik dengan Metode Pirolisis menjadi Bahan Bakar Minyak" adapun hasil yang di dapatkan dari sampel plastik $\mathrm{Pp}$ pada suhu $400^{\circ} \mathrm{C}$ sebanyak $27,05 \%$ dan sampel HDPE pada suhu $300 \stackrel{\circ}{\mathrm{C}}$ sebanyak $37,43 \%$.

Ini berarti semakin tinggi suhu yang di gunakan maka akan semakin baik hasil yang di dapatkan.

4. Alat Pirolisis mampu menurunkan berat sampah dengan pemanfaatan limbah plastik menjadi Bahan Bakar Minyak

Plastik adalah polimer rantai panjang dari atom yang mengikat satu sama lain. Rantai ini membentuk banyak unit molekul berulang, atau "monomer". Istilah plastik mencakup produk polimerisasi sintetik atau semisintetik, namun ada beberapa polimer alami yang termasuk plastik.

Adapun padatan dari hasil pirolisis plastik ini berupa padatan keras karena setelah penelitian sisa padatan langsung di keluarkan dari tabung pirolisis dan di diamkan sehingga terjadi kontak dengan udara yang menyebabkan sisa padatan mengeras.

Dari tabel 2, diperoleh penurunan berat plastik pada suhu $150{ }^{\circ} \mathrm{C}$ dengan lama waktu kontak adalah 60 menit. $\mathrm{Hal}$ ini disebabkan karena pengaruh suhu dengan waktu kontak sangat berkaitan, semakin tinggi suhu pemanasan maka zat-zat yang terkandung dalam plastik akan terurai menjadi rantai pendek. Penguraian senyawa - senyawa plastik menyebabkan terjadinya penurunan massa plastik yang ada di dalam reaktor. 
Zat-zat yang terkandung di dalam plastik PET akan terurai menjadi gas dan cair (minyak). Dengan demikian semakin lama waktu proses pembakaran terjadi maka berat plastik yang ada akan semakin turun.Pada proses pirolisis, menjaga suhu konstan merupakan faktor terpenting oleh karena itu suhu perlu diperhatikan.Karena sushu pembakaran adalah hal yang menentukan untuk pross penguraian plastik menjadi bahan bakar minyak. Adapun sisa padatan hasil pirolisis tersebut dapat digunakan ulang sebagai bahan campuran untuk aspal hal ini dibuktikan dengan penelitian Apriyadi Dwi Widodo, dkk (2017) yaitu "Pengaruh penambahan limbah botol plastik polypthylene terepthalate (PET) dalam campuran laston-wc terhadap parameter marshall".

Alat pengolah limbah sampah plastik sangat sesuai untuk digunakan dalam mengatasi masalah polusi lingkungan akibat sampah plastik yang sulit terurai. Seperti yang diketahui sampah plastik merupakan masalah yang sangat serius untuk ditanggulangi. Saat ini penanggulangan sampah plastik belum terlihat jelas, sampah plastik di bakar masih menjadi solusi yang sering dilakukan guna meminimalisir volume sampah. Jika penanggulangan sampah plastik hanya dengan pembakaran maka akan berdampak pada lingkungan sekitar, karena dapat mencemari lingkungan dan berdampak pada mahluk hidup disekelilingnya dikarenakan hasil pembakaran plastik menghasilkan gas dioksin yang bersifat karsinogen yang dapat menyebabkan gejala timbulnya kanker.

Selain dapat menimalisir volume sampah alat ini juga mampu menghasilkan bahan bakar alternatif guna mengatasi kelangkaan bahan minyak yang semakin meningkat. Alat ini bisa diproduksi massal dan digunakan ditempat pembuangan akhir sampah untuk mengatasi polusi lingkungan akibat sampah plastik yang ada di Indonesia.

Menurut Asosiasi Industri Plastik Indonesia (INAPLAS) dan Badan Pusat Statistik (BPS), sampah plastik di Indonesia mencapai 64 juta ton/ tahun dimana sebanyak 3,2 juta ton merupakan sampah plastik yang dibuang ke laut.
Menurut sumber yang sama,, kantong plastik yang terbuang ke lingkungan sebanyak 10 milliar lembar per tahun atau sebanyak 85.000 ton kantong plastik.

Sedangkan data yang di peroleh dari SIPSN (Sistem Informasi Pengolahan Sampah Nasional, 2018) tepatnya di kota Makassar dengan luas wilayah $175.77 \mathrm{Km}^{2}$ dengan jumlah jiwa per 2018 adalah 1.469.601 jiwa dapat menghasilkan 1.425 .00 ton/hari dengan persentasi sampah plastik sebesar $16.29 \%$.

\section{KESIMPULAN}

1. Alat pirolisator berupa pengolah limbah sampah plastik menjadi bahan bakar alternatif dengan menggunakan prinsip pirolisis dapat menghasilkan Bahan Bakar Minyak (BBM).

2. Alat Pirolisis kurang menghasilkan bahan bakar minyak saat pengolahan limbah plastik jenis PET dan HDPE dengan suhu $150 \stackrel{\circ}{\mathrm{C}}$.

3. Pemanfaatan $1 \mathrm{~kg}$ limbah plastik menjadi bahan bakar minyak (BBM) dapat menurunkan berat sampah plastik sebanyak : Limbah plastik Jenis PET $50 \%$, Limbah Plastik Jenis HDPE 40\%, dan Gabungan Limbah Plastik Jenis PET dan HDPE sebanyak $50 \%$

\section{SARAN}

Adapun maka saran yang diberikan untuk penelitian selanjutnya adalah :

1. Perlu dipasangi penangkap tar untuk mencegah terjadinya peledakan pada alat.

2. Memperhatikan alat agar tidak ada kebocoran pada tabung pirolisis dan kondensor

3. Memperhatikan air pada tabung kondensor agar selalu dingin.

4. Perlu menaikkan suhu pengolahan sampai pada titik didih $300^{\circ} \mathrm{C}$.

5. Harus selalu memperhatikan suhu pada saat proses berlangsung

6. Perlu dilakukan penelitian lanjutan tentang pengaruh suhu terhadap proses pirolisis plastik.

7. Apabila akan dikembangkan dalam skala produksi maka perlu diteliti lagi menggunakan reaktor jenis kontiniu, sehingga proses pengolahan bisa berlangsung terus menerus. 
Jurnal Sulolipu : Media Komunikasi Sivitas Akademika dan Masyarakat

Vol. 20 No.2 2020

e-issn : 2622-6960, p-issn : 0854-624X

\section{DAFTAR PUSTAKA}

Apriadi Dwi Widodo. 2017. Pengaruh Penambahan Limbah Botol Plastik Polypthylene Terepthalate (Pet) Dalam Campuran Laston-Wc Terhadap Parameter Marshall. Yogyakarta: Jurusan Teknik Sipil. (Online) http://tekniksipil.umy.ac.id/ wpcontent/uploads/2014/07/jurnalPKM-P-PET.pdf Diakses 19 Desember 2018

Bajus. M. dan Hajekova.E.. 2010. Thermal Cracking of The Model Seven Components Mixed Into Oils/Waxes. (Online) https://www. researchgate.net/publication/47394 502 Potroleum \& Coal 52 (3) 164172.Slovak University of Technology.Bratislava.Slovakia. Diakses 19 Desember 2018

BPS. 2016. Komposisi Sampah di Makassar. Makassar: Badan Pusat Statistik Dinas Pertamanan dan Kebersihan Kota Makassar. 2014. Jumlah total timbunan sampah di Makassar

Ihwan, Fajar. 2017. Bumi Dikepung Sampah Plastik, Eart Hour Makassar Buat Gerakan "Benci" Kantong Plastik : Greeneration (online) http://www.arsip.kabar. news.com. Diakses 11 Januari 2018.

Ismail. Ridho. Ahmad.2018. Pemanfaatan Limbah Plastik menjadi Bahan Bakar Minyak. Makassar:Jurusan Kesehatan Lingkungan.Poltekkes Makassar (Skripsi tidak diterbitkan).

Jambeck and Jenna R. 2015. Plastic Waste Inputs From Land Into The Ocean. Jurnal. 347.6223:768-771. (Online) https://wedocs.unep.org/bit .Diakses 20 Desember 2019

Kuncoro, Sucipto. 2015. Memahami Arti Kode Plastik dan Penggunaannya. http://www.pasiensehat.com/2015/0 1/arti-kode-plastik-dan-penggunaan nya.html Diakses 16 Januari 2019.

Maxmanroe.com. 2018. Pengertian Sampah Organik dan Anorganik, Jenis,Dampak dan Cara Penanganannya https://www.max manroe.com/vid/umum/pengertiansampah.html Diakses 19 Desember 2018.

Manurung, Nelson. 2017. Pembuatan Bahan Bakar Minyak dari Limbah Plastik dengan Menggunakan Dua Kondensor. (Online). JITEKH, Vol 6, No 1, Tahun 2017, 11-16. http://www.ejournal.stth-medan.ac. id/index.php/Jitekh Diakses 19 Desember 2018

Mohana. Jeya. Valli.. G.Gnanavel.. 2012. "Alternate Fuel From Synthetic Plastic Waste-Review". Vol 1(3). International Journal Of Pharmaceutical And Chemical Sciences. India. http:// www.ijpcs online.com/files/26-166.pdf Diakses 19 Desember 2018

Nasrun. Kurniawan. E.. dan Sari. I.. 2015. Pengolahan limbah kantong plastik jenis kresek menjadi bahan bakar menggunakan proses pirolisis. Jurnal Energi Elektrik Volume IV Nomor 1.(Online). https://doco book.com/queue/pengolahan-lim bah-kantong-plastik-jeniskresekmenjadi-bahan.html. Diakses 19 Desember 2018

Prasetyo. Hendra. Rudhiyanto. Fitrianto. Eka.l.. 2013. Mesin pengolahan limbah plastik menjadi bahan bakr minyak alternatif. Fakultas Teknik. Universits Negeri Semarang http://www.dikti.go.id/index .php/PKMT/566/566. Diakses 20 Desember 2018

(Online)

Republik Indonesia. 2008. Undang-Undang No. 18 Tahun 2008. tentang Pengelolaan Sampah.

Sejati.Kuncoro. 2009. Pengolahan Sampah Terpadu.Yogyakarta:Paska Peta

Sodikin Mandala Putra. 2011. Teknologi Pemanfaatan Batubara Untuk Menghasilkan Batubara Cair, Pembangkit Tenaga Listrik, Gas Metana Dan Briket Batubara. Palembang: Jurusan Teknik Pertambanngan Universitas Sriwijaya (Online) http://eprints. unsri.ac.id/138/1/Pages from PRO SIDING AVOER 2011-32.pdf Di Akses Pada Tanggal 20 Desember 2018. 
Jurnal Sulolipu : Media Komunikasi Sivitas Akademika dan Masyarakat

Vol. 20 No.2 2020

e-issn : 2622-6960, p-issn : 0854-624X

Surono. B.U.. dan Ismanto. 2016. Pengolahan Sampah Plastik Jenis PP, PET dan PE Menjadi Bahan Bakar Minyak dan Karakteristiknya. Yogyakarta: Fakultas Teknik, Universitas Janabadra. Jurnal.1 (1) : 32-37. (Online) http://e-journal. janabadra.ac.id/index.php/ JMST Diakses 20 Desember 2018

Sumarni. 2008. Kinetika Reaksi Pirolisis Plastik Low Density Poliethylene (LDPE). Yogyakarta :Jurusan Teknik Kimia,Institut Sains dan Teknologi (Online) http://www.Jurnal.umj. ac. id/ index. php/semnast ek. Diakses 20 desember 2018

Untoro, Budi Surono. April 2013, "Berbagai Metode Konversi Sampah Plastik Menjadi Bahan Bakar Minyak", Vol.3 No.1, Jurnal Teknik,Yogyakarta (Online) http://www.researchgate.net/publica tion/320296275. Diakses 11 Januari 2019

Wordpress. 2018. 5 Negara Penimbul Sampah Terbesar di Dunia. https://sampahmuda.com/blog/?p=43.diakses. tanggal 9 januari 2019.

Wahyudi. E.. Zultiniar. Saputra. E.. 2016. Pengolahan sampah plastic polipropilena ( pp ) menjadi bahan bakar minyak dengan metode perangkahan katalitik menggunakan katalis sintesis. Jurnal Rekayasa Kimia dan Lingkungan. Vol. 11, No.1, HImn ISSN 1412-5064, e-ISSN 23561661.(Online). https://www.doco book.com/pengolahan-sampahplastik-polipropilenapp.html. diakses 11 Januari 2019

Wardani.2009. Riset Sumber Daya Manusia. Jakarta: PT.Gramedia Pustaka

Wega. Trisunaryanti. 2012. Dari Sampah Plastik Menjadi Bensin dan Solar. Yogyakarta: Gadjah Mada University Press

Wasesa. S.R.. Hilal Nur.. dan Triyantoro Budi. 2016. Pengolahan Sampah Plastic Menjadi Bahan Bakar Dengan Alat Pengolahan Sampah Platik Fixed-Bed Reactor,Dua Kondensor. Keslingmas Vol. 35 Hal.152277. (Online). http://www. ejournal.poltekkessmg.ac.id/ojs/ind ex.php/keslingmas. Diakses 19 desember 2019 